\title{
Validation of the Copenhagen Burnout Inventory in Pharmacists
}

\author{
Olajide O. Fadare, BPharm ${ }^{1}$; Michael Andreski, PhD²; Matthew J. Witry, PharmD, PhD ${ }^{1}$
}

${ }^{1}$ University of lowa, lowa City, lowa; ${ }^{2}$ Drake University, Des Moines, lowa

\begin{abstract}
Objectives: This study aimed to 1) determine the validity of the Copenhagen Burnout Inventory (CBI) for use in the assessment of burnout in a sample of pharmacists using confirmatory factor analysis (CFA), and 2) use the CBI items and other measures of work-life to assess burnout in pharmacists employed in various types of practice.

Methods: A cross-sectional survey was administered to a sample of 2,582 pharmacists in a single Midwestern US state. The survey included the three subscales of the CBI, each of which measures personal, work-related, and patient-related dimensions of burnout. Other items included demographics, practice type, workload, and work-life balance. CFA was used to measure fit, and Cronbach's alpha was used to assess reliability. Correlation was used to assess criterion validity of the CBI. Logistic regression and bivariate analyses were used to assess pharmacist burnout based on demographics.

Results: Following the removal of 2 items from the measurement model, a 17-item 3-factor CBI was found to possess satisfactory psychometric properties for use in pharmacists. The CBI correlated with measures of work-life demonstrating criterion validity. A logistic regression showed that younger pharmacists and community pharmacists experience higher burnout than older pharmacists and clinical pharmacists. Community pharmacists also more often reported high workloads and poorer work-life integration. Both community and clinic pharmacists desired more time providing patient care services and less time dispensing.

Conclusion: The $\mathrm{CBI}$ is a psychometrically reliable and valid instrument for assessing burnout in pharmacists. Younger pharmacists and community pharmacists warrant attention due to their higher degree of burnout.
\end{abstract}

Keywords: Burnout, pharmacy, workload, work-life, measurement, survey

\section{Introduction}

The World Health Organization included burnout in the $11^{\text {th }}$ Revision of the International Classification of Diseases (ICD-11), conceptualizing it as an occupational phenomenon resulting from chronic workplace stress that has not been successfully managed. Burnout can be characterized using three dimensions 1) feelings of energy depletion or exhaustion, 2) increased mental distance or cynicism from one's job, and 3) reduced professional efficacy. ${ }^{1}$ Research suggests burnout is more prevalent in healthcare professionals relative to the general population. ${ }^{2}$ Factors contributing to burnout in healthcare include compounding emotional aspects of patient care, increased clerical and administrative tasks, reduced reimbursement, and fast-paced changes to practice. ${ }^{3}$ Burnout is associated with increased risk of medical errors, patients nonadherence to treatments, lower patient satisfaction, and also poses a threat to patient safety. ${ }^{4,5}$

The incidence and prevalence of burnout among physicians are well documented. ${ }^{3}$ Less research has investigated burnout in other professionals on the health care team. ${ }^{3,6}$ There are growing concerns about the negative impact of burnout on the professional well-being of pharmacists and the potential for similar effects on patient safety and outcomes. ${ }^{7}$ Some of these

Corresponding author: Matthew J. Witry, PharmD, PhD

University of lowa, lowa City, lowa State, US

Email: matthew-witry@uiowa.edu effects like decreased pharmacists' job satisfaction, ${ }^{8}$ reduced work engagement, ${ }^{9}$ and increased intention-to-leave and job turnover ${ }^{10,11}$ are related to the pharmacist's professional role, while other effects like increased risk of coronary heart disease due to exhaustion and fatigue, ${ }^{12}$ and sleep disturbances, ${ }^{13}$ affect the pharmacist in a more personal way. These concerns inform the need for meaningful assessments of burnout in pharmacists to guide the evaluation of interventions aimed at reducing burnout and improving pharmacist wellbeing.

Several instruments have been developed to measure burnout ${ }^{14}$, the most common is the Maslach Burnout Inventory (MBI). ${ }^{15,16}$ The $\mathrm{MBI}$ conceptualizes burnout as a composite of emotional exhaustion, depersonalization, and personal accomplishment and has been validated among physicians and nurses. ${ }^{17,18}$ Critics have pointed out that though the MBI supposes to measure burnout as one construct, rather, it represents three different constructs that should not be combined but measured and analyzed as distinct phenomena. This lack of fine correspondence between concept and measure could result in biased estimates of burnout. ${ }^{19,20}$ Another major limitation of the $\mathrm{MBI}$ is the proprietary nature which can contribute to a lack of transparency when reported. ${ }^{14,20}$

The Copenhagen Burnout Inventory ( $\mathrm{CBI}$ ) was designed to address some of the limitations of the $\mathrm{MBI} .^{20}$ The $\mathrm{CBI}$ is premised on two major theoretical considerations; the first being the conceptualization of burnout as fatigue or exhaustion, and the second being the theory of causal attribution. Schaufeli et al. (2001) and Pines et al. (1988) both define burnout as a state of physical, emotional, and mental 
exhaustion that results from long-term involvement in situations that are emotionally demanding. ${ }^{21,22}$ The theory of causal attribution posits that individuals engage in attributional analyses as they seek to understand, predict, and control events they are experiencing in their lives. ${ }^{23}$ Combining the experience of fatigue or exhaustion in workers with attribution, the CBI features three subscales intended to measure burnout based on three dimensions, that is, levels of causal attributions. One of the subscales labeled personal burnout (PB), is designed to be generic and applicable regardless of occupation. The other two subscales are labeled work-related burnout (WRB) which focuses on the individual's attribution of fatigue or exhaustion to their work, and client-related burnout which measures the degree of fatigue or exhaustion an individual attributes to their working directly with clients. In this study, we define clients as patients that pharmacists interact with in the course of their work and labelled this subscale as patientrelated burnout (PRB).

Although the authors of the $\mathrm{CBI}$ reported high internal reliability, face validity, and criterion validity for the items, the authors did not originally validate the three scales of the CBI using factor analysis based on the rationale that having three scales on the inventory was not a statistical decision, but rather, a theoretical decision. ${ }^{20}$ In a study on burnout among Australian dentists in which the $\mathrm{CBI}$ was compared with the MBI, Winwood et al. concluded that "the CBI possesses excellent psychometric properties [reliability] and seems to be an appropriate measure of burnout in populations of health professionals." ${ }^{24}$ The construct validity of the $\mathrm{CBI}$ and its suitability for assessing burnout in pharmacists is yet to be determined.

\section{Objective}

The objectives of this study were to 1 ) validate the $\mathrm{CBI} 3$-factor conceptualization of burnout for a sample of pharmacists using confirmatory factor analysis (CFA). 2) To use these factors to assess burnout in pharmacists employed in various types of practice.

\section{Methods}

Data collection

This study was a cross-sectional survey of lowa Pharmacists performed in 2019. A sample of 2,582 pharmacists were recruited for the study using a mixture of mailed and electronic self-administered surveys. The protocol was designed using elements of the Total Design Method. ${ }^{25}$ Duplicate sets of name and address mailing labels $(n=3,645)$ of all registered pharmacists who had an lowa mailing address were obtained from the lowa Board of Pharmacy. These names were compared to a list of e-mail addresses obtained from the lowa Pharmacy Association (IPA) membership database $(n=2,132)$. Pharmacists with emails were sent an invitation to complete the survey via web link. For the 1,513 pharmacists that only had an address, 450 were randomly selected to be sent a paper survey via postal mail due to budgetary constraints. Two weeks after the initial e-mailing and postal mailing, a reminder e-mail was sent to the e-mailed pharmacists and a reminder postcard was sent to the pharmacists who received a mailed survey. Instances where an e-mail was returned as being sent to an invalid address or when a postal mailing was returned were recorded and removed from the effective sample size. The final sample size was 2,589 .

The e-mails included information about the research and its voluntary nature and described the confidentiality protections for participants. The mailed surveys contained a cover letter with the same information as the e-mails and a paper copy of the survey. There was no tracking of participation for either the e-mailed or postal mailed surveys. Completion of any items in the survey was considered as a response for statistical purposes. IRB exemption was granted for this study by Drake University, Des Moines, lowa, US.

\section{Measures}

The $C B I$ is a 19-item measure that assesses three dimensions of burnout- personal burnout (PB), work-related burnout (WRB), and patient-related burnout (PRB). Personal burnout is conceptualized as burnout experienced by pharmacists regardless of job roles. Work-related burnout refers to burnout attributed by pharmacists to aspects of their work other than providing services directly to other humans (patients). Patientrelated burnout refers to burnout attributed by pharmacists to providing services directly to other humans (patients). ${ }^{20}$ The personal burnout scale includes six items such as "How often do you feel worn out?" which are scored on a five-point Likertscale of 1 (always) to 5 (never). The work-related burnout scale has seven items, for example, "Do you feel burnout because of your work?" scored on a five-point Likert scale of 1 (always) to 5 (never). The patient-related burnout scale includes six items such as "Does it drain your energy to work with patients?" also scored on a five-point Likert scale of 1 (always) to 5 (never).

The workforce survey also included pharmacist demographics (age, gender, ethnicity, educational experiences completed, and current licensing status), practice-type, as well as other indicators of burnout like current workload, work-life integration, and role conflict. Due to the low sample representation on most practice-types on the survey, practicetypes were grouped into two major categories of community pharmacists and clinical pharmacists for these analyses. Community pharmacists comprise the following: independent, small chain and large chain community pharmacies, mass merchandisers, and supermarket pharmacies. Clinical pharmacists comprise the following: clinic-based pharmacy, mail-service pharmacy, government and non-government hospital or health system, nursing homes, and home health. Pharmacy Benefit Associations (PBA), academic pharmacists, for-profit, and non-profit organizations were categorized as others. 


\section{Analysis}

Descriptive statistics for the respondents and the $\mathrm{CBI}$ items were computed. Cronbach's alpha and inter-item correlation were used to assess the reliability of the three subscales of the $\mathrm{CBI}$. We confirmed the fit of the 3-factor structure of the $\mathrm{CBI}$ in our sample by conducting confirmatory factor analysis (CFA). Missing data analysis was conducted and both univariate and multivariate outliers were assessed for exclusion from the CFA by examining standardized residuals, Cook's distance, and Mahalanobis distance as described by Bowen and Guo (2012). ${ }^{26}$ Both absolute and relative fit indices were used in model evaluation. These include model chi-square $\left(\chi^{2}\right)$, root mean square error of approximation (RMSEA), standardized root mean-square residual (SRMR), Tucker-Lewis index (TLI), and comparative fit index (CFI). SRMR cut point for model acceptance was 0.05. Perry et al. (2015) have suggested that conventional cut-off points of $>0.95$ for TLI and CFI, and RSMEA $<0.06$ may be too conservative in estimating the goodness of fit when a multifactorial instrument is evaluated in a diverse sample. ${ }^{27}$ Hence, we have adopted cut-off points of $>0.90$ for TLI and CFI, and RMSEA $<0.08$ as acceptable levels of fit for the CFA models in this study.

In an exploratory post-hoc analysis, the model with an admissible solution was respecified to further improve the fit. Re-specification was guided by considerations of the theoretical underpinnings of the $\mathrm{CBI}$, and inspection of modification indices, expected parameter change values, and standardized residuals to assure substantive justification. Also, within the CFA framework, a multigroup analysis was used to determine whether the $\mathrm{CBI}$ can be used to make inferences about burnout in a population of pharmacists independent of practice type.

The second study objective was addressed by conducting binomial logistic regression in which burnout was regressed on practice-type as the main explanatory variable with age and gender as covariates in the model. As part of the larger survey, the $\mathrm{CBI}$ measured burnout using 19 items on a 5-point scale with responses coded 1 for always, 2 for often, 3 for sometimes, 4 for seldom, and 5 for never. For the logistic regression, the dependent variable, burnout, was dichotomized into high burnout for respondents with median burnout score $<=3$, and low burnout for respondents with median burnout scores $>3$. Likewise, based on the scoring of the scale, lower mean scores indicate higher average burnout, and higher mean scores indicate lower average burnout. Other indicators of burnout included workload, work-life integration, and role conflict (measured as the difference between the desired time and the actual time spent on tasks at work) were compared across practice types using a series of bivariate analyses.

Criterion validity of the $\mathrm{CBI}$ items was assessed by testing correlations between the $\mathrm{CBI}$ and other factors associated with burnout; workload and work-life integration. A negative correlation was hypothesized between desirable work-life integration and high burnout, and a positive correlation was hypothesized between high workload and high burnout. Completion of any items in the survey was considered as a response, however, cases with missing data were excluded from certain analyses for statistical purposes. Analyses were performed in R v.4.0.0 at an a priori significance level of 0.05.

\section{Results}

Descriptive statistics

The survey had a valid response rate of $21.7 \%(561 / 2,589)$. The mean age for the study sample was 47 years $(S D=13.0)$ and ranged from 25 to 83 years. $41.4 \%$ were women. The mean number of years of practice for respondents was 22.1 years (SD $=13.5$ ) and ranged from 1 to 57 years. $26.0 \%$ of the total respondents worked as community pharmacists at the time of the study (Table 1).

Descriptive statistics for the $\mathrm{CBI}$ items and subscales are reported in Appendix $A$. The descriptive statistics for the $C B I$ items showed no substantial violation of the condition of normality required for CFA (Appendix A). Skewness and kurtosis were within acceptable levels based on a cut-off of $>|1| .^{28}$ Standardized residuals (SRESID > $>1.96$ ), Cook's distance (Cook's D > 1), and Mahalanobis distance $\left(D^{2} M, p<0.001\right)$ computed for the sample data identified 1 univariate outlier and 40 multivariate outliers that were excluded from the CFA analyses $(N=520)$. Each of the three subscales showed high internal reliability using Cronbach's alpha $\left(\alpha_{\mathrm{PB}}=0.93, \alpha_{\mathrm{WRB}}=\right.$ 0.81 , and $\alpha_{\mathrm{PRB}}=0.89$ ).

\section{Confirmatory Factor Analysis (CFA)}

Using the sample after removing outliers $(n=520)$, CFA was performed on the hypothesized covariance structure between the $19 \mathrm{CBI}$ items. In all the analyses, inter-factor correlations were allowed, each item (indicator variable) loaded on only one factor, latent factors were scaled by using one of the indicator variables as a reference indicator. The first model, Model 1 (Appendix B) was found to have an inadmissible solution on account of the presence of factor loading greater than 1.0 and a negative variance estimate for items PRB05 and PRB06. ${ }^{29}$ The model was re-specified to give model 2 by excluding these 2 items. Although model 2 (Appendix B) was found to have an admissible solution with a slightly better fit than model 1 , an unacceptable RMSEA level informed inspection of the model for localized areas of poor fit. Large values of modification indices, expected parameter change values, and standardized residuals revealed the possible omission of salient indicatorerror correlations between some items. The model was respecified to include indicator-error correlations that were deemed to make satisfactory substantive sense. Substantive justification for re-specification was based on the presence of effects that stem from the use of a multifactorial-multiple indicator questionnaire like the $\mathrm{CBI}$ as the assessment tool, and the similar wording of some of the questionnaire items. ${ }^{30}$ The re-specified model, that is model 3 (Appendix $B$ ), was found to have an adequate fit. Model 3 was retained as the final solution 
and used in subsequent analyses. All factor loadings were significant and had values above 0.40 (range $=0.58$ to 0.97 ). Path WRB04 with the lowest factor loading was also the only reversed-scored item in the $\mathrm{CBI}$ (Appendix $\mathrm{C}$ ).

Multi-group analysis conducted between community pharmacists ( $n=132)$, clinic-oriented pharmacists $(n=142)$, and pharmacists in other practice types $(n=68)$ showed that constraints of an equal number of factors, equal factorindicator pattern, and equal factor loadings did not significantly degrade the fit of the model $\left[\chi_{\text {diff }}^{2}=121.86, \mathrm{df}_{\text {diff }}=28, \mathrm{p}=1.0\right]$, suggesting that the measurement of burnout by the $\mathrm{CBI}$ was invariant equal across groups. Fit indices for CFA models are presented in Appendix C.

Statistically significant positive correlation in the hypothesized direction was found between workload and $\mathrm{CBI}$ items $\left[r_{\mathrm{PB} / \mathrm{WLD}}=\right.$ $\left.0.43, r_{W R B / W L D}=0.472, r_{P R B / W L D}=0.20(p<0.001)\right]$, and statistically significant negative correlation in the hypothesized direction was found between work-life integration and $\mathrm{CBI}$ items $\left[r_{\mathrm{PB} / \mathrm{WLI}}=-0.55, \mathrm{r}_{\mathrm{WRB} / \mathrm{WLI}}=-0.57, \mathrm{r}_{\mathrm{PRB} / \mathrm{WLI}}=-0.34(\mathrm{p}<0.001)\right]$, providing evidence of criterion validity for the $\mathrm{CBI}$.

\section{Logistic Regression}

In the binomial logistic regression model (Table 2 ), age was a significant predictor of high burnout in pharmacists $(p=$ $0.0303)$. In terms of practice-type, relative to the community practice-type as the reference group, clinical practice-type was the only significant predictor of high burnout $(p<0.001)$. As shown in table 5 , the odds of pharmacists in clinical practicetype experiencing high burnout is $0.39(0.23,0.65)$ times the odds of community pharmacists experiencing high burnout. Gender was not a significant predictor of high burnout in this sample of pharmacists. Overall, on average, burnout for community pharmacists was significantly higher than for clinical pharmacists on each of the subscales ( $p<0.001)$, and average burnout for pharmacists decreased from younger to older age groups.

\section{Bivariate Analyses}

As shown in Table 3, tests of difference in proportions showed that a significantly higher proportion of community pharmacists than clinical pharmacists reported their current workload to be high ( $p=0.004)$ and had negative work-life integration ( $p=$ 0.015). Also, while on average, both community pharmacists and clinical pharmacists reported spending more time than they desired on medication dispensing, patient care services, and administrative tasks, and less time than they desired training and mentoring, Wilcoxon rank-sum test showed that conflict in roles was more significant for community pharmacists than for clinical pharmacists.

\section{Discussion}

The $\mathrm{CBI}$ is designed to measure burnout across three dimensions- personal life experiences (PRB subscale), workrelated burnout (WRB subscale), and interaction with patients at work (PRB). ${ }^{20}$ Our assessment of criterion validity show that the $\mathrm{CBI}$ measures the construct burnout, and our validation process confirmed this hypothesized three-factor structure for burnout to function adequately in pharmacists and derived a more parsimonious instrument by removing 2 patient-related burnout (PRB) items from the $\mathrm{CBI}$ that did not fit the data adequately. Also, findings from our analysis comparing practice types show equality of factor loadings which indicates that the $\mathrm{CBI}$ is suitable for use in measuring burnout among pharmacists across different practice- settings. Also, the high internal reliability, significant factor loadings for each subscale, and consistency of the CBI's factor structure across different practice settings support the CBI authors' position that at any time, any of the subscales can be used to assess burnout independent of other subscales. This is especially important for heterogeneous populations like pharmacists where burnout may be experienced differently by different groups such that the focus for some practice settings might be work-related burnout rather than patient-related burnout or vice-versa. Though this is the first study to examine the suitability of the $\mathrm{CBI}$ for use in pharmacists, our findings are consistent with Winwood et al.'s (2004) study that provided evidence for the use of $\mathrm{CBI}$ in its entirety among Australian dentists. ${ }^{24}$ Therefore, we propose the $\mathrm{CBI}$ as a valid measure for pharmacy researchers to assess burnout in pharmacists. ${ }^{20}$

Using a reduced 17-item $\mathrm{CBI}$ to assess burnout in a population of US pharmacists, the risk of high burnout appeared to decrease with increasing age, with pharmacists younger than 30 years having the highest risk of high burnout suggesting that age is a protective factor against burnout. This trend is consistent with the findings of other studies showing that older workers are better at using positive adaptive and emotion regulation skills acquired through life experiences which makes them more engaged on the job and less burnt out when faced with stressful situations. ${ }^{31-34}$ With older pharmacists, previous encounters with stressful situations serve to boost their feelings of confidence and increases their ability to anticipate and prepare in advance for potentially difficult situations compared to younger, less experienced pharmacists. ${ }^{34,35}$

Also, pharmacists in clinical practice were less likely to report high burnout on the $\mathrm{CBI}$ compared to pharmacists in community practice as community pharmacists reported experiencing significantly higher levels of work-place stressors like excessive workload, negative work-life balance, and role conflicts compared to clinical-practice pharmacists. This disparity between community pharmacists and clinic pharmacists could be due to increasing prescription volume combined with declining reimbursement rates which puts increased demand on community pharmacists to fill more prescriptions and provide more administrative and billing services related to prescription management. ${ }^{36-39}$ Also, although there has been an increase in pharmacy services like immunizations and medication reviews, community pharmacists still spend significantly more of their time on 
routine medication dispensing than on activities like providing patient care services. ${ }^{40}$ This dissonance between tasks that pharmacists find the most meaningful and the reality of their daily work tasks contributes to a sense of dissatisfaction as pharmacists feel that their skills are being underused. ${ }^{40,41}$ Further, pharmacists may experience moral injury when they consistently fail to meet the needs of their patients. ${ }^{42}$ Hence, efforts to reduce and prevent burnout in pharmacists can be directed at aligning job roles with pharmacists' perception of meaning. For example, shifting the focus of dispensing to a practice of continuous medication monitoring may increase pharmacist engagement in their work. ${ }^{43}$

Burnout, left unaddressed, has detrimental personal and organizational consequences for pharmacists and pharmacy practice. ${ }^{19}$ For instance, burnout has been identified as a key determining factor of high pharmacist turnover and intent to leave or change jobs. ${ }^{44} \mathrm{High}$ pharmacist turnover is associated with suboptimal quality of care for patients, ${ }^{45}$ and also diminishes the returns on pharmacists' professional training by constantly seeking job opportunities outside their current place of employment due to a sense of dissatisfaction and disengagement from their work. ${ }^{45-48}$ As is the case with physicians and health care professionals who share similar training and professional obligations with pharmacists, personal or psychological burnout due to consistent exposure to patient-suffering which draws empathy from the pharmacist and leaves them with emotional injuries, ${ }^{49}$ has been associated with increased risk of mental health challenges like depression and suicidal ideation among pharmacists. ${ }^{50-52}$ The problem of burnout-induced suicidal ideation in pharmacists is further complicated by the reluctance of pharmacists to become patients themselves which makes them less likely to voluntarily disclose their challenges for timely intervention. ${ }^{53}$

\section{Limitations}

Data for this study was collected from a survey of pharmacists in a single midwestern state in the US. This reduces the generalizability of the findings to other populations of pharmacists that may differ from our study population in ways that are uniquely relevant to their experience of burnout. Also, the response rate for the study survey was somewhat low $(21.67 \%)$ which could suggest the potential for non-response bias if those completing the survey had different characteristics and experiences than those that did not complete the survey. Because of the small sample and a significant proportion of respondents skipping the demographic questions, individual practice-types could not be used as a unit of analysis which limited our ability to explore burnout at specific levels of practice-type.

\section{Future Research}

Further studies are needed to explore how pharmacists might differ in their experience of burnout based on specific causal attributions as represented by each of the subscales of the CBI, using a more diverse pharmacy population and considering the impact of the COVID-19 pandemic on pharmacists' well-being. Also, future research would include modeling the effect of interactions between the three dimensions of the $C B I$ on burnout and examining potential reverse causal pathways between pharmacists' experience of burnout and relevant personal and work factors. Also, more research is needed to explore the relationship between other aspects of pharmacists' work experience and burnout, such as perceived control, social support from peers, colleagues, and supervisors, moral distress, work-place discrimination, and harassment. Reporting overall averages and trends, however, is likely to miss the nuances and lived experiences of individual pharmacists which also would provide meaningful insight into the phenomena of pharmacist work-life and burnout. There are important differences between how researchers study burnout and work-life, and how employers should monitor the wellness and engagement of their staff which warrant more exploration, including a greater focus on fulfillment and wellness. ${ }^{54}$ More work is needed on professional wellness and work engagement, including using qualitative methods.

\section{Conclusion}

This study provides evidence for the validity and reliability of the $\mathrm{CBI}$ as an instrument for assessing burnout in community pharmacists and clinical-practice pharmacists. Focus should be placed on community pharmacists and younger pharmacists due to their significantly higher levels of burnout. More nuanced investigations of work-life are needed, as are evidence-based Interventions.

Funding: This survey was supported in part by the lowa Pharmacy Association. However, the funder was not involved in the research.

Conflict of Interest: We declare no conflicts of interest or financial interests that the authors or members of their immediate families have in any product or service discussed in the manuscript, including grants (pending or received), employment, gifts, stock holdings or options, honoraria, consultancies, expert testimony, patents, and royalties.

Treatment of Human subjects: IRB exemption granted 


\section{Reference}

1. World Health Organization. Burn-out an "Occupational Phenomenon": International Classification of Diseases. WHO. https://www.who.int/news/item/28-05-2019-burnout-an-occupational-phenomenon-internationalclassification-of-diseases. Published 2019. Accessed 06/19, 2020.

2. lacovides A, Fountoulakis KN, Kaprinis S, Kaprinis G. The Relationship between Job Stress, Burnout, and Clinical Sepression. J Affect Disord. 2003;75(3):209-221.

3. Dyrbye LN, Shanafelt TD, Sinsky CA, et al. Burnout Among Health Care Professionals: a Call to Explore and Address this Underrecognized Threat to Safe, High-Quality Care. NAM Perspectives. 2017.

4. Hall LH, Johnson J, Watt I, Tsipa A, O'Connor DB. Healthcare Staff Wellbeing, Burnout, and Patient Safety: A Systematic Review. PLOS ONE. 2016;11(7):e0159015.

5. Panagioti M, Geraghty K, Johnson J, et al. Association Between Physician Burnout and Patient Safety, Professionalism, and Patient Satisfaction: A Systematic Review and Meta-analysis. JAMA Intern Med. 2018;178(10):1317-1330.

6. Kang K, Absher R, Granko RP. Evaluation of Burnout Among Hospital and Health-system Pharmacists in North Carolina. Am J Health Syst Pharm. 2020;77(6):441-448.

7. Traynor K. Coalition Seeks Solutions for Clinician Burnout. Am J Health Syst Pharm. 2017;74(17):1296-1297.

8. Ortmeier BG, Wolfgang AP. Job-related Stress: Perceptions of Employee Pharmacists. Am Pharm. 1991;Ns31(9):27-31.

9. Gaither CA. Career Commitment: A Mediator of the Effects of Job Stress on Pharmacists' Work-Related Attitudes. J Am Pharm Assoc (1996). 1999;39(3):353-361.

10. Mott DA. Pharmacist Job Turnover, Length of Service, and Reasons for Leaving, 1983-1997. Am J Health Syst Pharm. 2000;57(10):975-984.

11. Gaither CA, Nadkarni A, Mott DA, et al. Should I stay or should I go? The Influence of Individual and Organizational Factors on Pharmacists' Future Work Plans. J Am Pharm Assoc (2003). 2007;47(2):165-173.

12. Toker S, Melamed S, Berliner S, Zeltser D, Shapira I. Burnout and Risk of Coronary Heart Disease: A Prospective Study of 8838 Employees. Psychosomat Med. 2012;74(8).

13. Yeh YC, Lin BY, Lin WH, Wan TT. Job Stress: its Relationship to Hospital Pharmacists' Insomnia and Work Outcomes. Int J Behav Med. 2010;17(2):143-153.

14. Prasad-Reddy L, Kaakeh R, McCarthy B. Burnout Among Health System Pharmacists: Presentation, Consequences, and Recommendations. Hospital Pharm. 2020:001857872091039.

15. Dolan ED, Mohr D, Lempa M, et al. Using a Single Item to Measure Burnout in Primary Care Staff: a Psychometric Evaluation. J Gen Intern Med. 2015;30(5):582-587.

16. Maslach C, Jackson SE. Maslach Burnout Inventory: Manual. Consulting Psychologists Press; 1986.

17. Poghosyan L, Aiken LH, Sloane DM. Factor Structure of the Maslach Burnout Inventory: an Analysis of Data from Large Scale Cross-sectional Surveys of Nurses from Eight Countries. Int J Nurs Stud. 2009;46(7):894-902.

18. Rafferty JP, Lemkau JP, Purdy RR, Rudisill JR. Validity of the Maslach Burnout Inventory for Family Practice Physicians. J Clin Psychol. 1986;42(3):488-492.

19. McQuade BM, Reed BN, DiDomenico RJ, Baker WL, Shipper AG, Jarrett JB. Feeling the Burn? A Systematic Review of
Burnout in Pharmacists. J Am College Clin Pharm. 2020;3(3):663-675.

20. Kristensen TS, Borritz M, Villadsen E, Christensen KB. The Copenhagen Burnout Inventory: A New Tool for the Assessment of Burnout. Work \& Stress. 2005;19(3):192-207.

21. Pines A, Aronson E. Career burnout: Causes and cures. New York, NY, US: Free Press; 1988.

22. chaufeli WB, Greenglass ER. Introduction to Special Issue on Burnout and Health. Psychol Health. 2001;16(5):501-510.

23. Weary G, Reich, D. A. Attribution theories.In: Kazdin IAE, ed. Encyclopedia of psychology. Vol 1. Washington: American Psychological Association.; 2000:320-325.

24. Winwood $P$, Winefield A. Comparing Two Measures of Burnout Among Dentists in Australia. Int J Stress Manag. 2004;11:282.

25. Hoddinott SN, Bass MJ. The Dillman Total Design Survey Method. Can Fam Physician. 1986;32:2366-2368.

26. Bowen NK, Guo S. Structural Equation Modeling. Oxford University Press, USA; 2012.

27. Perry J, Clough PJ, Crust L, Nabb SL, Nicholls AR. Development and Validation of the Compliant and Principled Sportspersonship scale (Pre-published version). 2014.

28. Tabachnick BG, Fidell LS. Using Multivariate Statistics. Pearson Education; 2013.

29. Chen F, Bollen KA, Paxton P, Curran PJ, Kirby JB. Improper Solutions in Structural Equation Models: Causes, Consequences, and Strategies. Sociol Methods \& Res. 2001;29(4):468-508.

30. Podsakoff $P$, MacKenzie S, Lee JY, Podsakoff N. Common Method Biases in Behavioral Research: A Critical Review of the Literature and Recommended Remedies. J App Psychol. 2003;88:879-903.

31. Jones GM, Roe NA, Louden L, Tubbs CR. Factors Associated With Burnout Among US Hospital Clinical Pharmacy Practitioners: Results of a Nationwide Pilot Survey. Hosp Pharm. 2017;52(11):742-751.

32. Maslach C, Schaufeli WB, Leiter MP. Job Burnout. Ann Rev Psychol. 2001;52(1):397-422.

33. Dyrbye LN, Varkey P, Boone SL, Satele DV, Sloan JA, Shanafelt TD. Physician Satisfaction and Burnout at Different Career Stages. Mayo Clinic Proceed. 2013;88(12):1358-1367.

34. Charles ST, Carstensen LL. Emotion regulation and aging. 2007.

35. Charles ST, Piazza JR. Age Differences in Affective Wellbeing: Context Matters. Soc Personal Psychol Compass. 2009;3(5):711-724.

36. Gidman WK, Hassell K, Day J, Payne K. The Impact of Increasing Workloads and Role Expansion on Female Community Pharmacists in the United Kingdom. Res Social Adm Pharm. 2007;3(3):285-302.

37. Cooksey JA, Knapp KK, Walton SM, Cultice JM. Challenges to the Pharmacist Profession from Rscalating Pharmaceutical Demand. Heal Affairs. 2002;21(5):182-188.

38. Zellmer WA. The Role of Pharmacy Organizations in Transforming the Profession: the Case of Pharmaceutical Care. Pharm Hist. 2001;43(2/3):75-85.

39. Shanafelt TD, Noseworthy JH. Executive Leadership and Physician Well-being: Nine Organizational Strategies to Promote Engagement and Reduce Burnout. Mayo Clinic Proceed. 2017;92(1):129-146. 
40. Schommer JC, Gaither CA, Doucette WR, Kreling DH, Mott DA. Associations between work activity and work setting categories and dimensions of pharmacists' quality of work life. Pharmacy. 2018;6(3):62.

41. Mott DA, Doucette WR, Gaither CA, Pedersen CA, Schommer JC. Pharmacists' Attitudes Toward Worklife: Results from a National Survey of Pharmacists. J Am Pharm Assoc (2003). 2004;44(3):326-336.

42. Wendy Dean SGT. Physicians Aren't 'Burning Out.' They are Suffering from Moral Injury.

https://www.statnews.com/2018/07/26/physicians-notburning-out-they-are-suffering-moral-injury/. Published 2018. Accessed10/23/2020.

43. Goedken AM, Butler CM, McDonough RP, Deninger MJ, Doucette WR. Continuous Medication Monitoring (CoMM): A Foundational Model to Support the Clinical Work of Community Pharmacists. Res Social Adm Pharm. 2018;14(1):106-111.

44. Liu CS, White L. Key Determinants of Hospital Pharmacy Staff's Job Satisfaction. Res Social Adm Pharm. 2011;7(1):51-63.

45. Panagioti M, Geraghty K, Johnson J, et al. Association Between Physician Burnout and Patient Safety, Professionalism, and Patient Satisfaction: A Systematic Review and Meta-analysis. JAMA Intern Med. 2018;178(10):1317-1331.

46. Mahoney CD, Gallina JN, Jeffrey LP. A Comprehensive Program to Increase Job Satisfaction Among Pharmacy Technicians. Hosp Pharm. 1982;17(10):547-550.
47. Al-Muallem N, Al-Surimi KM. Job Satisfaction, Work Commitment and Intention to Leave Among Pharmacists: a Cross-Sectional Study. BMJ Open. 2019;9(9):e024448.

48. Gaither CA, Kahaleh AA, Doucette WR, Mott DA, Pederson CA, Schommer JC. A Modified Model of Pharmacists' Job Stress: The Role of Organizational, Extra-role, and Individual Factors on Work-related Outcomes. Res Soc Admin Pharm. 2008;4(3):231-243.

49. Rakesh G, Pier K, Costales TL. A Call for Action: Cultivating Resilience in Healthcare Providers. Am J Psychiat Resident. 2017;12(4):3-5.

50. Williams E, Martin SL, Fabrikant A, Wang A, Pojasek M. Rates of Depressive Symptoms Among Pharmacy Residents. Am J Health Syst Pharm. 2018;75(5):292-297.

51. Dyrbye LN, Thomas MR, Massie FS, et al. Burnout and Suicidal Ideation Among U.S. Medical Students. Ann Intern Med. 2008;149(5):334-341.

52. Marshall LL, Allison A, Nykamp D, Lanke S. Perceived Stress and Quality of Life Among Doctor of Pharmacy Students. Am J Pharm Educ. 2008;72(6):137-137.

53. Moutier C, Cornette M, Lehrmann J, et al. When Residents Need Health Care: Stigma of the Patient Role. Acad Psychiatry. 2009;33(6):431-441.

54. Eckleberry-Hunt J, Van Dyke A, Lick D, Tucciarone J. Changing the Conversation From Burnout to Wellness: Physician Well-being in Residency Training Programs. J Grad Med Educ. 2009;1(2):225-230. 
Table 1: Description of participants ( $N=561)$

\begin{tabular}{|c|c|c|}
\hline Characteristic & N (\%) & *Mean (SD) \\
\hline \multicolumn{3}{|l|}{ Gender } \\
\hline Male & $112(20.0)$ & $3.38(0.69)$ \\
\hline Female & $232(41.4)$ & $3.10(0.71)$ \\
\hline Missing & $217(38.6)$ & - \\
\hline \multicolumn{3}{|l|}{ Age (years) } \\
\hline$\leq 30$ years & $44(7.8)$ & $3.07(0.72)$ \\
\hline $31-40$ years & $84(15.0)$ & $3.13(0.74)$ \\
\hline $41-50$ years & 78 (13.9) & $3.20(0.77)$ \\
\hline $51-60$ years & $65(11.6)$ & $3.24(0.75)$ \\
\hline$>60$ years & $68(12.1)$ & $3.55(0.81)$ \\
\hline Missing & $222(39.6)$ & - \\
\hline \multicolumn{3}{|l|}{ Practice Type } \\
\hline Community Pharmacy & $146(26.0)$ & $2.95(0.74)$ \\
\hline Independent & $n=44$ & \\
\hline Small Chain & $n=7$ & \\
\hline Large Chain & $n=47$ & \\
\hline Mass Merchandiser & $n=20$ & \\
\hline Supermarket pharmacy & $n=28$ & \\
\hline Clinical practice & $158(28.2)$ & $3.30(0.74)$ \\
\hline Clinic-based pharmacy & $n=11$ & \\
\hline Mail Service pharmacy & $n=2$ & \\
\hline Government Hospital & $n=28$ & \\
\hline Non-government Hospital & $n=16$ & \\
\hline Nursing home & $n=84$ & \\
\hline Home health & $n=17$ & \\
\hline Others & $48(8.6)$ & $3.52(0.72)$ \\
\hline${ }^{1}$ PBMs & $n=8$ & \\
\hline Academia & $n=4$ & \\
\hline For-Profit Organization & $n=3$ & \\
\hline Non-Profit Organization & $n=33$ & \\
\hline Missing & 209(37.3) & - \\
\hline
\end{tabular}

*average burnout; lower values indicate higher burnout

${ }^{1}$ PBM = Pharmacist Benefit Managers, $\quad n$ = subgroup sample size 
Table 2: Logistic Regression predicting high burnout=1 versus low burnout=0

\begin{tabular}{|c|c|c|c|c|}
\hline & \multirow[b]{3}{*}{ Beta (SE) } & \multirow{2}{*}{\multicolumn{3}{|c|}{$\begin{array}{l}95 \% \mathrm{Cl} \text { for Odds } \\
\text { Ratio }\end{array}$}} \\
\hline & & & & \\
\hline Predictor & & Lower bound & Odds Ratio & Upper bound \\
\hline Intercept & $1.39(0.37)$ & 1.97 & 4.03 & 8.51 \\
\hline Age & $-0.23(0.11)^{*}$ & 0.64 & 0.79 & 0.98 \\
\hline \multicolumn{5}{|c|}{ Practice Type: Community (Reference) } \\
\hline Clinical & $-0.95(0.26)^{* *}$ & 0.23 & 0.39 & 0.64 \\
\hline \multirow{2}{*}{\multicolumn{5}{|c|}{$\begin{array}{c}\text { Other } \\
\text { Gender: Man (Reference) }\end{array}$}} \\
\hline & & & & \\
\hline Woman & $0.19(0.20)$ & 0.80 & 1.20 & 1.79 \\
\hline
\end{tabular}

${ }^{* *} p<0.001$

${ }^{*} p=0.009$

Table 3: Bivariate analysis of burnout across practice-types

Difference in proportions

\begin{tabular}{|c|c|c|c|c|c|}
\hline Indicator & $\mathbf{p}_{\text {community }}$ & $\mathbf{p}_{\text {clinical }}$ & Diff. in $p$ & $95 \% \mathrm{Cl}$ & $p$-value \\
\hline High current workload & 0.65 & 0.48 & 0.17 & $0.053,0.286$ & 0.004 \\
\hline Negative work-life integration & 0.41 & 0.27 & 0.14 & $0.033,0.257$ & 0.015 \\
\hline \multicolumn{6}{|l|}{ Role Conflict } \\
\hline & \multicolumn{2}{|c|}{ Community } & \multicolumn{2}{|c|}{ Clinical } & \\
\hline Work Activities & $\begin{array}{l}\text { Mean (SD) } \\
\text { actual time } \\
\text { spent }\end{array}$ & $\begin{array}{l}\text { Mean (SD) } \\
\text { desired time }\end{array}$ & $\begin{array}{l}\text { Mean (SD) } \\
\text { actual time } \\
\text { spent }\end{array}$ & $\begin{array}{l}\text { Mean (SD) } \\
\text { desired time }\end{array}$ & p value* \\
\hline Medication dispensing & $70.62(23.11)$ & $53.94(22.73)$ & $\begin{array}{l}37.74 \\
(29.73)\end{array}$ & $26.84(25.49)$ & $<0.001$ \\
\hline Provision of patient care services & $14.05(11.00)$ & $29.78(30.00)$ & $\begin{array}{l}25.13 \\
(30.00)\end{array}$ & $45.75(28.08)$ & $<0.001$ \\
\hline Business & $8.80(16.84)$ & 7.64 (14.63) & 15.41 & $13.17(25.18)$ & 0.03 \\
\hline Organization/Management & & & $(26.60)$ & & \\
\hline Training and Mentoring & $3.50(5.16)$ & $6.36(7.60)$ & $5.08(6.00)$ & $8.36(11.34)$ & 0.24 \\
\hline
\end{tabular}

$\mathrm{p}=$ proportion

* test of significant difference in role conflict between community pharmacists and clinical pharmacists 
Appendix A: Exploratory descriptive statistics of the 19 CBI items

\begin{tabular}{lllllll}
\hline item & Mean & SD & Median & Skew & Kurtosis & IIC \\
\hline PB01 & 2.372 & 0.93 & 2 & 0.676 & 0.515 & 0.55 \\
PB02 & 2.791 & 1.06 & 3 & 0.17 & -0.623 & 0.55 \\
PB03 & 2.729 & 1.07 & 3 & 0.269 & -0.479 & 0.59 \\
PB04 & 3.505 & 1.14 & 4 & -0.4 & -0.644 & 0.61 \\
PB05 & 2.791 & 1.06 & 3 & 0.202 & -0.407 & 0.62 \\
PB06 & 3.751 & 1.04 & 4 & -0.721 & -0.005 & 0.51 \\
WRB01 & 2.477 & 1.09 & 2 & 0.287 & -0.597 & 0.59 \\
WRB02 & 3.314 & 1.17 & 3 & -0.301 & -0.713 & 0.60 \\
WRB03 & 3.899 & 1.13 & 4 & -0.752 & -0.39 & 0.57 \\
WRB04 & 2.386 & 0.94 & 2 & 0.499 & 0.073 & 0.41 \\
WRB05 & 2.866 & 1.06 & 3 & 0.046 & -0.496 & 0.58 \\
WRB06 & 2.852 & 1.00 & 3 & -0.069 & -0.479 & 0.57 \\
WRB07 & 3.119 & 1.16 & 3 & -0.051 & -0.735 & 0.63 \\
PRB01 & 3.726 & 0.92 & 4 & -0.16 & -0.747 & 0.44 \\
PRB02 & 3.668 & 0.95 & 4 & -0.32 & -0.149 & 0.46 \\
PRB03 & 3.643 & 0.85 & 4 & -0.025 & -0.52 & 0.45 \\
PRB04 & 3.217 & 1.13 & 3 & -0.118 & -0.729 & 0.34 \\
PRB05 & 3.144 & 0.78 & 3 & 0.071 & -0.235 & 0.68 \\
PRB06 & 3.444 & 0.80 & 3 & -0.157 & 0.103 & 0.62 \\
\hline PBP
\end{tabular}

$\mathrm{PB}=$ personal Burnout, $\mathrm{WRB}=$ Work-Related Burnout, $\mathrm{PRB}=$ Patient-Related Burnout IIC = Inter-Item Correlation 
Appendix B: Summary of goodness-of-fit indices for different measurement models

\begin{tabular}{|l|c|c|c|c|c|c|c|c|c|}
\hline Model & $\chi^{2}$ & $\mathbf{d f}$ & $\mathbf{p}$ & CFI & TLI & SRMR & RMSEA & RMSEA CI & Comment \\
\hline Model 1 & 3223.89 & 149 & $<0.001$ & 0.985 & 0.985 & 0.099 & 0.199 & {$[0.193,0.205]$} & $\begin{array}{l}\text { Inadmissible } \\
\text { solution }\end{array}$ \\
\hline Model 2 & 743.72 & 116 & $<0.001$ & 0.996 & 0.996 & 0.051 & 0.102 & {$[0.095,0.109]$} & $\begin{array}{l}\text { Admissible solution } \\
\text { with poor fit }\end{array}$ \\
\hline $\begin{array}{l}\text { Model 3 with indicator- } \\
\text { error correlations }\end{array}$ & 527.73 & 111 & $<0.001$ & 0.998 & 0.997 & 0.045 & 0.085 & {$[0.079,0.092]$} & $\begin{array}{l}\text { Retained solution; model } \\
\text { with a satisfactory fit }\end{array}$ \\
\hline
\end{tabular}

Appendix C: Standardized factor loadings for the final model (Model 3)

\begin{tabular}{lcc}
\hline Item & $\boldsymbol{\lambda}$ & $\mathbf{9 5 \%} \mathbf{C l}$ \\
\hline PB01 & 0.839 & {$[0.815,0.863]$} \\
PB02 & 0.876 & {$[0.855,0.897]$} \\
PB03 & 0.918 & {$[0.903,0.933]$} \\
PB04 & 0.907 & {$[0.889,0.923]$} \\
PB05 & 0.953 & {$[0.942,0.965]$} \\
PB06 & 0.744 & {$[0.707,0.781]$} \\
WRB01 & 0.908 & {$[0.891,0.925]$} \\
WRB02 & 0.835 & {$[0.811,0.859]$} \\
WRB03 & 0.817 & {$[0.787,0.846]$} \\
WRB04_rev & 0.589 & {$[0.641,0.536]$} \\
WRB05 & 0.886 & {$[0.866,0.905]$} \\
WRB06 & 0.835 & {$[0.808,0.861]$} \\
WRB07 & 0.972 & {$[0.962,0.981]$} \\
PRB01 & 0.963 & {$[0.943,0.983]$} \\
PRB02 & 0.970 & {$[0.951,0.988]$} \\
PRB03 & 0.957 & {$[0.938,0.976]$} \\
PRB04 & 0.633 & {$[0.568,0.698]$} \\
\hline X & &
\end{tabular}

$\lambda$ factor loadings
$p<0.001$ for all factor loadings 